\title{
Deciphering the Platinized Surface Reactivity to Improve the Detection of Hydrogen Peroxide in Bioanalyses
}

\author{
Vasilica Badets ${ }^{[a, b]+}$, Justine Pandard ${ }^{[a]}$, Neso Sojic ${ }^{[a]}$ and Stéphane Arbault ${ }^{\star[a]}$
}

\begin{abstract}
The reactivity of platinized electrode surface (Pt-black) was deciphered towards the oxidation of hydrogen peroxide in the most common physiological buffer, namely phosphate buffer saline, used in the development of biosensors. It is shown here that the oxidation of hydrogen peroxide by Pt-black involves first the adsorption of phosphate anions, which facilitates the oxidation of hydrogen peroxide at lower potentials when compared to classic polycrystalline platinum. This gives insight to the excellent analytical features of platinized electrodes for the detection of $\mathrm{H}_{2} \mathrm{O}_{2}$, even at nanomolar concentrations. The reactivity of platinized electrodes can be further improved by an oxygen plasma treatment. We demonstrate herein that such treatment creates an outermost layer of $\mathrm{PtO}_{2}$ oxides on the deposit, which improves thermodynamically and kinetically the oxidation of hydrogen peroxide, as well as of hydroquinone and superoxide radical anion.
\end{abstract}

\section{Introduction}

The Reactive Oxygen Species (ROS), including at least hydrogen peroxide $\left(\mathrm{H}_{2} \mathrm{O}_{2}\right)$, superoxide anion $\left(\mathrm{O}_{2}^{\circ}\right)$, hydroxyl radical $\left(\mathrm{OH}^{\circ}\right)$, singlet oxygen $\left({ }^{1} \mathrm{O}_{2}\right)$ play an essential role in multiple pathways of aerobic cell metabolism. Their monitoring is thus crucial to gain understanding of ROS consequences on both physiological and pathological processes, such as respiration, apoptosis, protein synthesis and lipid peroxidation. Since a majority of the ROS and RNS (reactive nitrogen species) are electroactive, they have thus become the target of electrochemical sensors development for biomedical applications. Apart from the numerous biosensors that have been reported, such as the peroxidase- or cytochrome $c$ modified electrodes, ${ }^{[1-7]}$ many research efforts have been devoted to structured metallic electrode surfaces. In particular, it is known for more than a century that platinum is an excellent catalyst for

[a] University of Bordeaux, ISM, CNRS UMR 5255, NSysA group, ENSCBP, F-33607 Pessac, France

[b] Université de Strasbourg, Institut de Chimie, UMR CNRS 7177 Laboratoire d 'Electrochimie et de Chimie Physique du Corps Solide 67081 Strasbourg, France

* Corresponding author : Dr. Stéphane Arbault; E-mail: stephane.arbault@enscbp.fr; Tel: +33540008939

${ }^{\dagger} \mathrm{V}$. Badets has previously published under the maiden name of $\mathrm{V}$. Lates

Supporting information for this article is given via a link at the end of the decomposition of hydrogen peroxide. It has thus been used under multiple forms and structures (polycrystalline, monocrystalline, nanoscopic, mesoscopic, etc.) for the electroanalysis of $\mathrm{H}_{2} \mathrm{O}_{2}{ }^{[8-10]}, \mathrm{O}_{2}{ }^{\circ}{ }^{[11-13]}$, as well as of their mother species, di-oxygen $\left({ }^{3} \mathrm{O}_{2}\right){ }^{[14-16]}$.

Among these surfaces, the nanostructured platinum deposits, quoted as platinum black (Pt-black) because of their light absorbance property, have raised much interest over the last three decades. In particular, Amatore et al. have shown that platinum black could be deposited on flat carbon or platinum electrodes of various size (millimetric to micrometric) and geometry (disk, band) ${ }^{[17]}$. Interestingly, they have shown that platinized microelectrodes are very efficient electroanalytical tools for the selective detection of different ROS-RNS in aqueous buffers and biological media: primarily $\mathrm{H}_{2} \mathrm{O}_{2}$, but also nitric oxide $\left(\mathrm{NO}^{\circ}\right)$, nitrite $\left(\mathrm{NO}_{2}^{-}\right)$, nitroxyl (NO-) and peroxynitrite (ONOO-) anions [17-21]. Moreover, it was shown that platinized ultramicroelectrodes provide the required analytical features (size, response-time, linear response over a large concentration domain) to monitor successfully the dynamic of ROS and RNS production by living systems at multiple scales: tissue, cell population, single cell or organelles ${ }^{[18-20]}$. The good compatibility between platinum black surfaces and biological systems has been illustrated by the incorporation of this material in the construction of implantable electrodes ${ }^{[22-24]}$ and in the fabrication of numerous biosensors, among which glucose biosensors occupy an important part ${ }^{[25-29]}$. In general, the great sensitivity achieved by these biosensors is explained by both the roughness, and consequently high surface-area of the platinum black deposits, and the catalytic activity of this material toward the

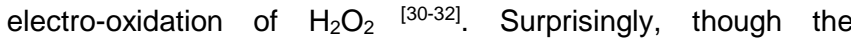
mechanism of this reaction has been extensively studied on polycrystalline platinum electrodes ${ }^{[33-39]}$, little is known about what happens exactly on platinum black and which features provide specific activity to this surface.

A recent study has shown that, in the case of electro-oxidation of high concentrations of hydrogen peroxide (about hundreds of millimolar), the local decrease of $\mathrm{pH}$ inhibits the active sites of platinum black, shifts the oxidation wave to higher potentials and leads to additional oxidation waves ${ }^{[40]}$. Additionally, our group has shown that the electroanalysis of low $\mathrm{H}_{2} \mathrm{O}_{2}$ concentrations (nanoto micromolar range) could be improved owing to a physical treatment by oxygen plasma of the platinized surfaces ${ }^{[41]}$. Lower capacitive currents as well as faster electron transfer rates for hydrogen peroxide oxidation were observed by modulating the oxidation state of platinum black electrode surface. The control of 
platinum oxidation state is of significant importance for industrial catalytic processes such as $\mathrm{CO}$ oxidation, $\mathrm{NO}_{x}$ reduction, oxidation of volatile organic compounds, etc. It is demonstrated that platinum oxides affect the thermodynamics and kinetics of various anodic reactions through multiple pathways including i) the change of electronic properties of the surface; ii) the creation of a charge transfer barrier; iii) the interaction with adsorbed reactants, intermediates or final products via a site-blocking effect. The oxidation of platinum is predominantly achieved via electrochemical anodization under highly acidic conditions ${ }^{[42-45]}$ or via reactive sputtering $[46,47]$ but more rarely via plasma treatments ${ }^{[48,49]}$.

In this context, this paper is aimed at understanding further the properties of platinum black surfaces and particularly the mechanism of oxidation of hydrogen peroxide in phosphate buffer at physiological $\mathrm{pH}$ (7.4), which is a key process for many types of biosensors. The role of the medium for analyses, namely of phosphate ion adsorption in the overall oxidation mechanism was evidenced; the hypothesis was reinforced by comparing the oxidation waves for $\mathrm{H}_{2} \mathrm{O}_{2}$ with responses of hydroquinone and superoxide anion solutions at platinum black electrodes. Finally, the importance of platinum oxides in these electro-oxidation processes was studied under modulation by an oxygen plasma treatment and reduction-oxidation potential scanning of the platinum black surfaces.

\section{Results and Discussion}

Deciphering the electro-oxidation mechanism of $\mathrm{H}_{2} \mathrm{O}_{2}$ at platinum black electrodes

Platinum black-modified electrodes were obtained by a potentiostatic electrodeposition in a hexachloroplatinic acid bath prepared in phosphate buffer (PBS, pH 7.4) according to a wellknown method ${ }^{[18-20,41]}$. SEM imaging (Figure 1) shows the typical "cauliflower" structure of Pt-black deposits that presents both micrometric and nanometric roughnesses. At the lower scale, we observe that the surface is developing from the growth of $\mathrm{Pt}$ needles of $100 \mathrm{~nm}$ mean dimension. We further analyzed this crystalline structure of Pt-black surfaces by XRD spectroscopy (Figure 2). We characterized a ratio between platinum crystallographic planes, (111):(210):(110), that is very different from the one of polycrystalline metallic platinum on which the deposit was grown: $1 / 0.3 / 0.25$ and $1 / 0.3 / 7$, respectively. This may explain some of the specific catalytic properties of Pt-black reported so far and herein (see below).
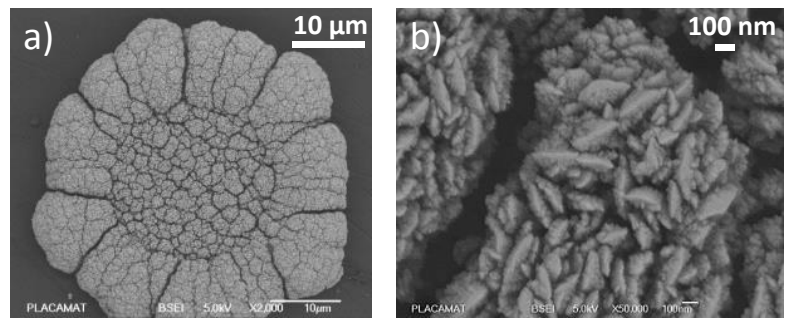

Figure 1. SEM imaging at two different magnifications of a platinum black deposit on a Pt microelectrode.

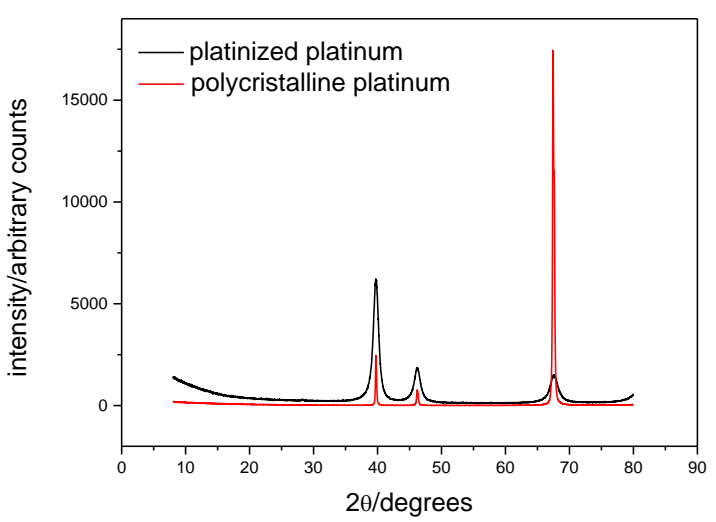

Figure 2. XRD spectra of a polycrystalline platinum microelectrode $(25 \mu \mathrm{m}$ diameter) before and after platinization.

Then, platinized microelectrodes were employed for the electro-oxidation of $\mathrm{H}_{2} \mathrm{O}_{2}$ in bioanalytical conditions, i.e. at $\mathrm{pH} 7.4$ in phosphate buffer (10 $\mathrm{mM}$ phosphate concentration). In comparison with polycrystalline platinum microelectrodes, which provide a single oxidation wave in voltammetry (Figure 3a), peaking around $0.6 \mathrm{~V}$ vs. $\mathrm{Ag} / \mathrm{AgCl}$ and a slow transfer kinetic profile ${ }^{[41]}$, a wave is observed at platinum black modified electrode with much faster kinetic reaching a plateau current at about $0.3 \mathrm{~V}$ vs $\mathrm{Ag} / \mathrm{AgCl}$ (Figure $3 \mathrm{~b}$ ). Therefore, a shift of about $300 \mathrm{mV}$ is gained, which improves very significantly the selectivity of biological measurements. However, we also observed two complementary facts; first, $\mathrm{H}_{2} \mathrm{O}_{2}$ solutions at concentrations higher than $2 \mathrm{mM}$ exhibit a second oxidation wave on Pt black electrodes (Figure 4, full line) with a plateau potential close to 0.65 $\mathrm{V}$ vs $\mathrm{Ag} / \mathrm{AgCl}$. The presence of two oxidation waves at $\mathrm{pH} 7.4$ is somewhat unexpected. Even if two electrons-two protons are involved in the oxidation process, these are commonly transferred in a single wave on polycrystalline $\mathrm{Pt}{ }^{[50]}$. Secondly, when hydrogen peroxide oxidation is analyzed in an electrolyte solution of $0.1 \mathrm{M} \mathrm{NaClO}_{4}$ ( $\mathrm{pH} 7.4$ unbuffered), a single oxidation wave is observed at the same potential as the second wave recorded in PBS (Figure 4, dash line). Therefore, it is evidenced here that phosphate anions play an important role in the mechanism, especially in the presence of the first oxidation wave. This mechanism is similar to the one proposed by Hall et al [33-37] 
regarding the oxidation of hydrogen peroxide on polycrystalline platinum electrode and phosphate buffer (Scheme 1).

$\mathrm{Pt}_{\mathrm{PS}}+\mathrm{H}_{2} \mathrm{PO}_{4}^{-} \leftrightarrow \mathrm{Pt}_{\mathrm{BS}}$

$\mathrm{Pt}_{\mathrm{BS}}+\mathrm{M} \leftrightarrow \mathrm{Pt}(\mathrm{M})_{\text {ads }}$

$M_{\text {ads }} \leftrightarrow M^{n+}+n e-$

Scheme 1. Oxidation mechanism of several species (denoted with $M$ ) on platinum black electrode and in phosphate buffer solutions.

The first step is the adsorption of phosphate at a pre-binding site (PS) on the platinum black surface, leading to the formation of a binding site (BS; equation 1 in scheme 1). Secondly, hydrogen peroxide adsorbs on this site facilitating energetically its oxidation (equation 2 and 3 in scheme1). If the phosphate species are not present, hydrogen peroxide reactivity is apparently different. It may adsorb directly on the platinum electrode, prior to its oxidation, possibly on a different reactive site at the surface. The key step of this mechanism is the adsorption of phosphate species $\left(\mathrm{H}_{2} \mathrm{PO}_{4}^{-}\right.$and $\left.\mathrm{HPO}_{4}^{-}\right)$. This phenomenon is well documented on platinum single crystal and polycrystalline electrodes [51-54]; it is clear from present data that phosphate adsorption on black platinum electrodes occurs as well. As shown in Figure 5a, this adsorption gives rise in PBS to a well-defined anodic peak, with an onset potential at $0.23 \mathrm{~V}$ and peak potential at $0.37 \mathrm{~V}$, and a less defined cathodic reverse wave. These peak and wave disappear in sodium perchlorate electrolyte $(\mathrm{pH} 7.4$, unbuffered).

Further, the competition between phosphate adsorption and formation of "Pt-O" surfaces oxides was taken into consideration [52]. When comparing Pt-black and polycrystalline Pt surface responses, the two phenomena are not clearly separated on polycrystalline platinum since they both display an onset potential at $0.23 \mathrm{~V}$ vs. $\mathrm{Ag} / \mathrm{AgCl}$, while on platinum black phosphate adsorption appears at a lower potential $(0.23 \mathrm{~V})$ than the onset of platinum oxides at $0.63 \mathrm{~V}$ (Figure $5 \mathrm{~b}$ ). Hence, the oxidation wave for hydrogen peroxide, reported at potentials above $0.6 \mathrm{~V}$ at polycrystalline electrode, can be explained by the fact that phosphate adsorption (essential for the adsorption of hydrogenated species) is hindered by the formation of surface oxides. On platinum black surface, the phosphate adsorption is clearly separated from the formation of surface oxides and thus the oxidation waves of these species appear at lower potentials, i.e. between 0.3 and $0.6 \mathrm{~V}$. Other differences between platinized and polycrystalline platinum are observed in the $\mathrm{H}_{\text {adsorption }} / \mathrm{H}_{\text {desorption }}$ fingerprints and for the reduction of surface oxides. Specifically, $\mathrm{H}_{\text {desorption }}$ appears at a more positive potential and the reduction peak at a more negative potential on platinized platinum compared to polycrystalline electrode (Figure $5 \mathrm{~b}$ ). These differences can be explained, in part, by the difference in the crystalline structure between black and polycrystalline platinum (Figure 2), but also by the high roughness factor of black $\mathrm{Pt}$ compared to polycrystalline $\mathrm{Pt}$, as reported elsewhere ${ }^{[24]}$, and by the presence of chlorine in the PBS buffer. It is important to note here that the same differences between the two electrodes were observed in an electrolyte containing only $0.1 \mathrm{M} \mathrm{NaClO}_{4}$ at $\mathrm{pH}$, but they were not observed in electrolyte containing only $0.5 \mathrm{M}$ $\mathrm{H}_{2} \mathrm{SO}_{4}$ (data not shown). They are also an indication about the differences that are encountered for the oxidation of severa species at black platinum when compared with polycrystalline platinum.
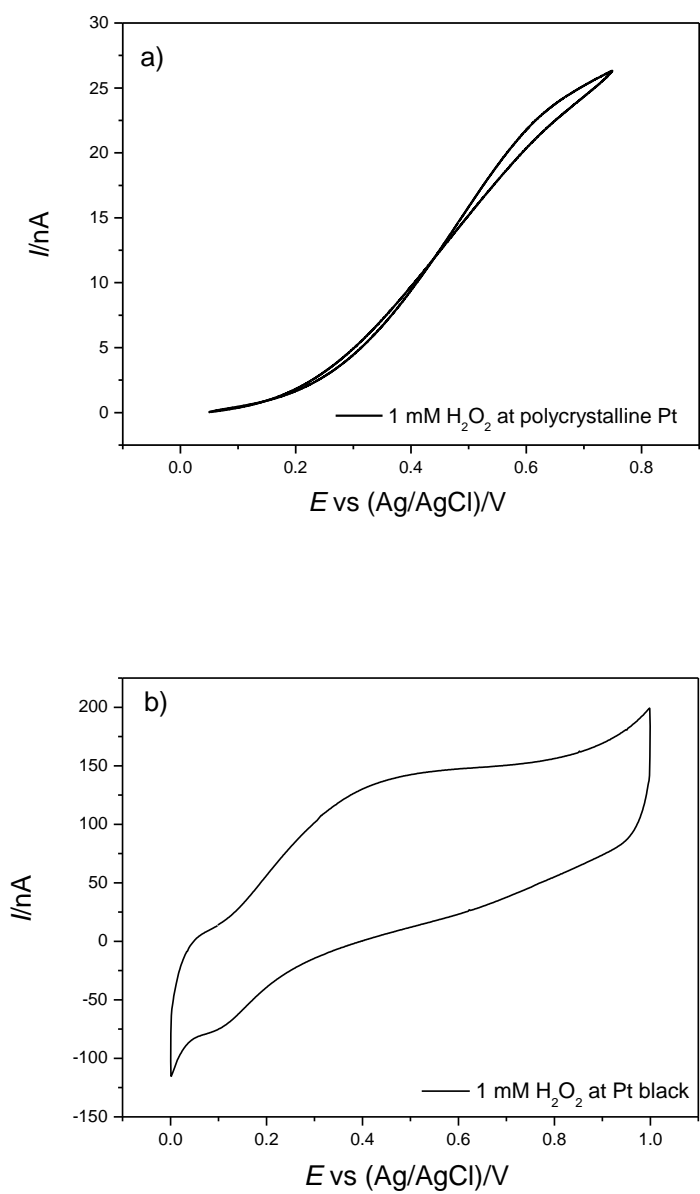

Figure 3. Hydrogen peroxide oxidation at polycrystalline and Pt-black electrodes. Experimental conditions: $1 \mathrm{mM} \mathrm{H}_{2} \mathrm{O}_{2}$ in air equilibrated PBS $\mathrm{pH} 7.4$; platinization charge, $800 \mu \mathrm{C}$; scan rate, $20 \mathrm{mV}^{-\mathrm{s}^{-1}}$. 


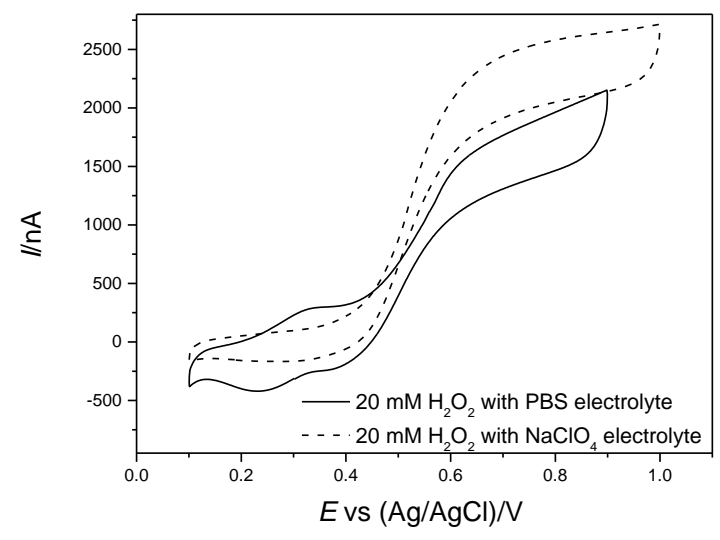

Figure 4. $\mathrm{H}_{2} \mathrm{O}_{2}$ oxidation at $\mathrm{Pt}$ black electrodes in two different electrolyte solutions. Experimental conditions: $\mathrm{H}_{2} \mathrm{O}_{2} 20 \mathrm{mM}$ in air equilibrated PBS pH 7.4 or air equilibrated $0.1 \mathrm{M} \mathrm{NaClO}_{4} \mathrm{pH} 7.4$; platinization charge, $800 \mu \mathrm{C}$; scan rate, $20 \mathrm{mV} . \mathrm{s}^{-1}$.
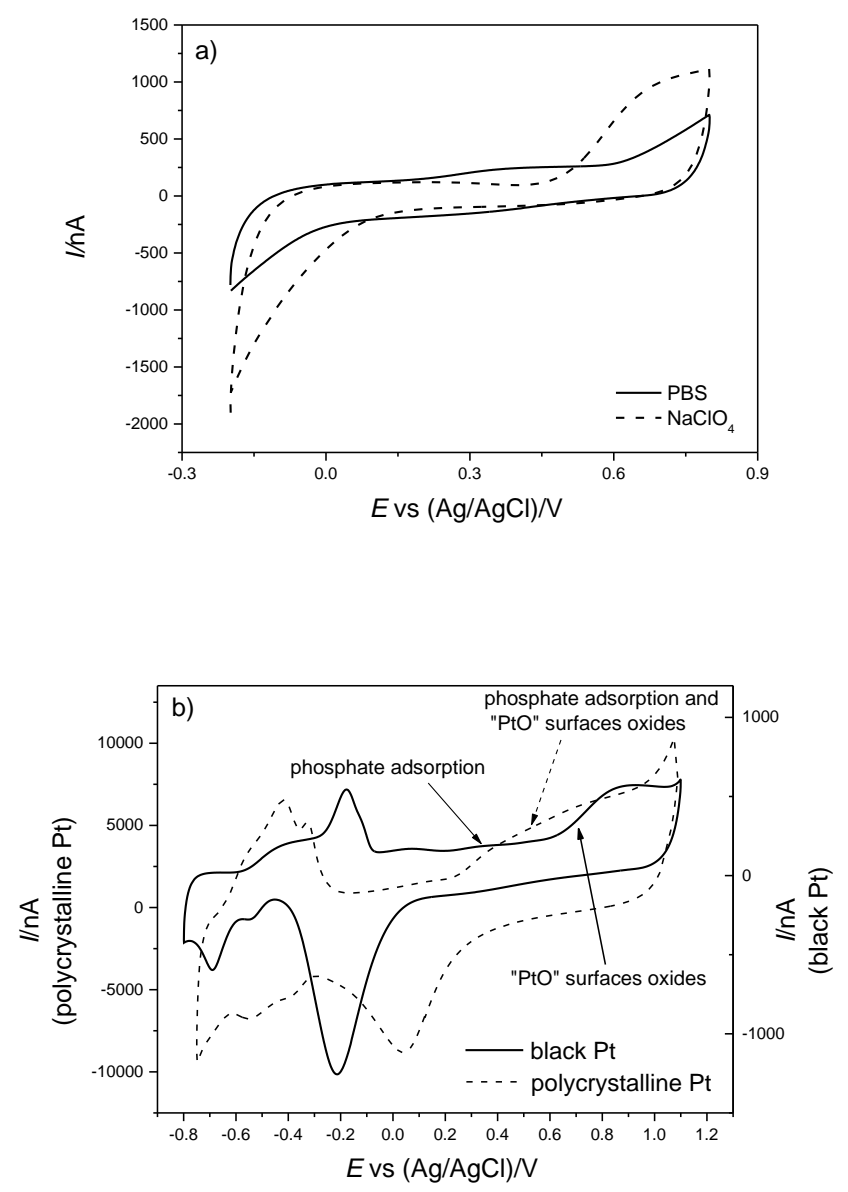

Figure 5. a) Voltammetric responses of platinized electrodes in phosphate buffer saline (PBS) and sodium perchlorate; b) Comparison of voltammetric profile of polycrystalline platinum and platinum black electrodes in phosphate buffer saline (PBS). Experimental conditions: electrolyte, $\mathrm{N}_{2}$ saturated PBS pH 7.4 or $0.1 \mathrm{M} \mathrm{NaClO}_{4} \mathrm{pH} 7.4$; platinization charge, $800 \mu \mathrm{C}$; scan rate, $20 \mathrm{mV}^{-\mathrm{s}^{-1}}$ for platinum electrode and $100 \mathrm{mV} . \mathrm{s}^{-1}$ for platinized platinum electrode.

The second step of the mechanism involves the adsorption of $\mathrm{H}_{2} \mathrm{O}_{2}$ on the binding site created by the adsorption of phosphate. This favors energetically the electron transfer and gives rise to the first oxidation wave detected by cyclic voltammetry. Interestingly, we observed that another hydrogenated species similar to $\mathrm{H}_{2} \mathrm{O}_{2}$, that is hydroquinone, follows the same trend and provides also an oxidative wave at low potentials in PBS (Figure 6) on the platinized electrodes. Moreover, both species, hydrogen peroxide and hydroquinone, are detected also at higher potentials, providing a second wave (close to $0.6 \mathrm{~V}$ vs. $\mathrm{Ag} / \mathrm{AgCl}$ ) on Pt-black electrodes. This is observed only when concentration of hydrogen peroxide or of hydroquinone rises above few millimolars.

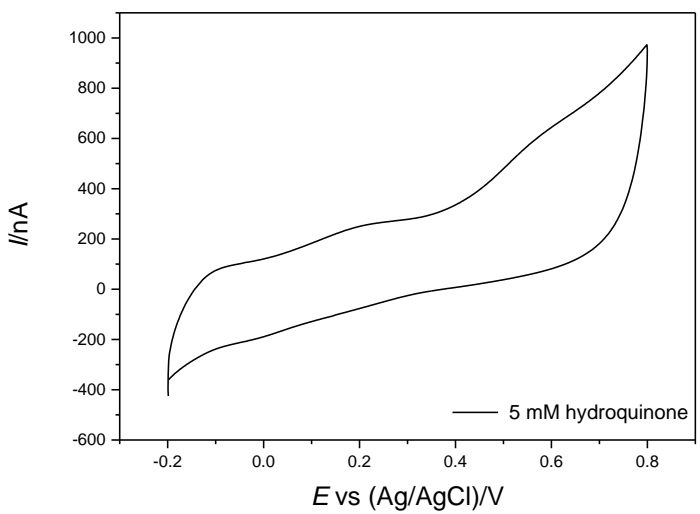

Figure 6. Voltammetry of hydroquinone oxidation at a platinized electrode. Experimental conditions: the hydroquinone solution is at $5 \mathrm{mM}$ in an air equilibrated PBS pH 7.4; platinization charge, $800 \mu \mathrm{C}$; scan rate, $20 \mathrm{mV}^{-\mathrm{s}^{-1}}$.

Consequently, we hypothesized that the first oxidation process detected below $0.4 \mathrm{~V}$, which depends on adsorption should reach a limit when all adsorption sites would be occupied. In order to check this hypothesis, the influence of the species concentration on both waves has been studied (Figure 7). For hydrogen peroxide, the current intensity of both waves varies linearly up to a concentration of about $10 \mathrm{mM}$, with a better sensitivity being observed for the first wave (Figure 7a). For higher concentrations, a change in the slope is observed, the sensitivity of the first wave becomes low (about 50-fold lower) while the second wave current increases linearly. These results are in agreement with the ones of Kicela et al., who reported two waves for the oxidation of hydrogen peroxide at black platinum electrodes, and a dependence on the roughness factor of electrode surface and the strength of the phosphate buffer ${ }^{[40]}$. The appearance of the second wave was noticed at $100 \mathrm{mM}$ for a phosphate buffer of $0.2 \mathrm{M}$ while in the present work, the appearance of the second wave is observed at $2 \mathrm{mM}$ for an usual 
phosphate buffer of $0.01 \mathrm{M}$. For hydroquinone, the first wave offers a high sensitivity for concentrations lower than $10 \mathrm{mM}$, reaching further a plateau-limit, while the second wave presents a single fairly linear evolution for the entire domain of concentrations (up to $50 \mathrm{mM}$ ) (Figure 7b). Both species present thus a very similar electrochemical behavior showing the importance of the phosphate-dependent interaction with the PtBlack surface. Nevertheless, from an analytical point of view, we confirm herein that a much higher sensitivity is obtained at low potentials, based on detecting the first oxidation wave. This is a major advantage of the platinized surface for the development of biosensors and other electro-analytical tools where nano to micromolar concentrations in phosphate buffer, mainly of $\mathrm{H}_{2} \mathrm{O}_{2}$, must be measured.
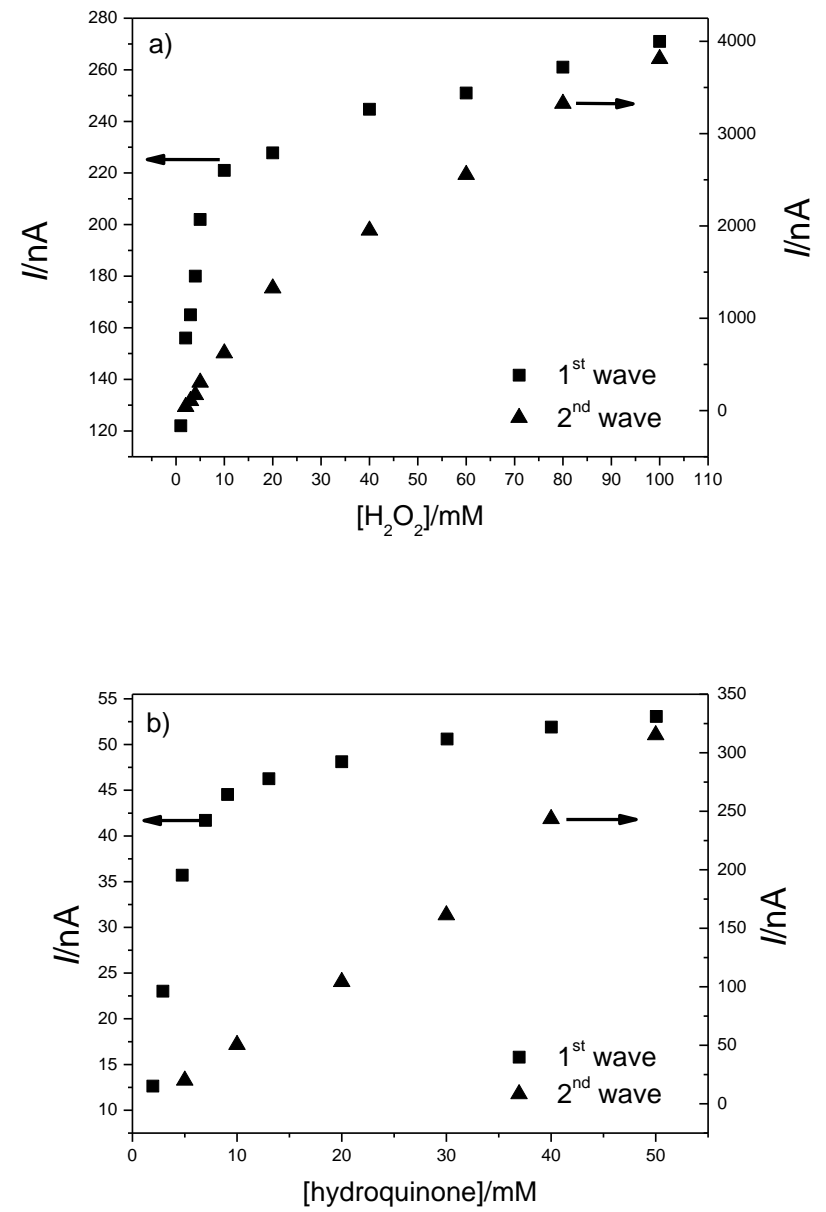

Figure 7. Influence of the concentration of species (hydrogen peroxide and hydroquinone) in PBS on their first and second oxidation wave detected by cyclic voltammetry at platinized microelectrodes (experimental conditions of Figures 4 and 6).

\section{Oxygen plasma treatment of platinum black electrodes}

In the process of improving the analytical properties and understanding the reactivity of platinized microelectrodes, we have recently shown ${ }^{[41]}$ that an oxygen plasma treatment reduces markedly their capacitive current in cyclic voltammetry and the corresponding root-mean-square noise in chronoamperometry measurements. These effects allowed to improve the sensitivity (3-fold) of hydrogen peroxide detection (10 nM Limit of Detection) and to monitor a flux of few hundreds picomoles $\mathrm{H}_{2} \mathrm{O}_{2} /$ min released during the respiration of mitochondria ${ }^{[41]}$. All effects were observed in the potential window of the first oxidation wave for $\mathrm{H}_{2} \mathrm{O}_{2}$ analyzed above. Consequently, a better understanding of the influence of oxygen plasma treatment on the oxidation mechanism of $\mathrm{H}_{2} \mathrm{O}_{2}$, and hydroquinone, became necessary. Platinized microelectrodes were subjected to an oxygen plasma treatment (20 min, 750 mTorr of $100 \%$ oxygen). The creation of platinum surface oxides was studied by XPS. Figure 8 shows the comparison of XPS spectra in the Pt $4 f$ region obtained before and after treatment of the same microelectrode. The new peak appearing at $77.4 \mathrm{eV}$ and corresponding to $\mathrm{Pt} 4 \mathrm{f}_{5 / 2}$ is a conclusive evidence of the formation of $\mathrm{PtO}_{2}$-type platinum oxides. This result is consistent with previously reported formation of $\mathrm{PtO}_{2}$ prepared by either anodization ${ }^{[42,55]}$ or plasma treatment ${ }^{[56]}$. Compared with oxygen plasma treatment of $\mathrm{Pt}$ thin films or nanoparticles [49], PtO-type oxides could not be detected on the treated platinized electrodes. This could be explained by the low power plasma device (18 W compared to $100 \mathrm{~W}{ }^{[56]}$ ) that was used in the present work. XPS spectra were also collected in depth $(0.2-80 \mathrm{~nm})$ and the presence of $\mathrm{PtO}_{2}$ is confirmed only at the extreme surface of the Pt-black deposit.

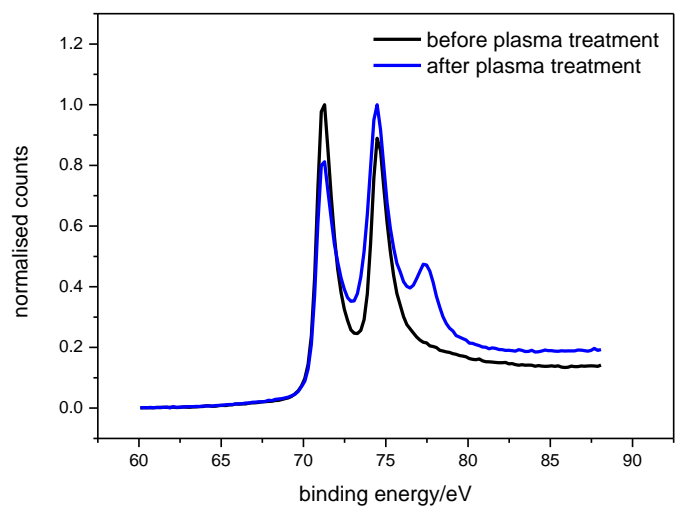

Figure 8. X-ray photoelectron spectra of Pt4f taken before and after the oxygen plasma treatment of platinized microelectrodes. Experimental conditions of the oxygen plasma treatment: $100 \% \mathrm{O}_{2}$ at 750 mTorr; plasma power, $18 \mathrm{~W}$; treatment time of $20 \mathrm{~min}$.

The presence of $\mathrm{PtO}_{2}$ was also evidenced by electrochemical experiments. Figure 9 presents the cyclic voltammograms obtained before and after the oxygen plasma treatment in a degassed sulfuric acid electrolyte. Before the 
treatment, the well-known reduction peak at $0.43 \mathrm{~V}$ of $2 \mathrm{D}$ surface platinum oxides ${ }^{[57]}$ is observed. After plasma treatment, the electrode potential was directly cycled in the reduction direction and two observations could be made: i) the characteristic reduction peak is displaced to a lower potential $(0.34 \mathrm{~V})$ and ii) a new reduction shoulder appears at $0.29 \mathrm{~V}$. Both of these observations point out the existence of surface oxides with a higher oxidation state, such as $\mathrm{Pt}^{\mathrm{IV}}$. These results are very similar to the ones reported for the formation of $\mathrm{PtO}_{2}-3 \mathrm{D}$ oxides obtained

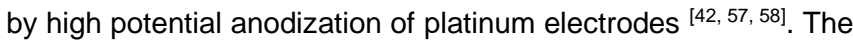
displacement of the $2 \mathrm{D}$ oxides reduction peak to lower potentials after the creation of 3D oxides is also well-known for the platinum electrodes ${ }^{[58]}$. In this later case, the higher the potential at which the anodic oxide film is formed, the lower (less positive) is the potential required for the reduction of this film. This irreversible behavior, that is opposite to thermodynamic expectations, is explained by the fact that the reduction process is not microscopically the reverse of the oxidation reaction (surface hysteresis) ${ }^{[58]}$. The complete reduction of $\mathrm{PtO}_{2}$ created by the oxygen plasma is observed during the second cycle (Figure 9) where the characteristic reduction peak returns to its normal position $(0.43 \mathrm{~V})$, and neither other shoulder nor additional peak is observed. The disappearance of $\mathrm{PtO}_{2}$ oxides after the electrochemical reduction was confirmed also by XPS spectra in which only the Pt $4 \mathrm{f}$ peaks characteristic of metallic platinum were observed (see supplementary Figure S1).

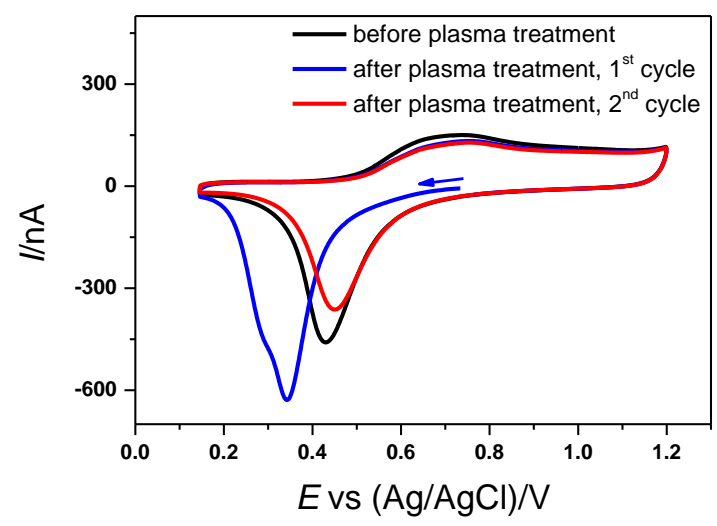

Figure 9. Cyclic voltammetry responses of a platinized microelectrode before and after an oxygen plasma treatment. Experimental conditions: $\mathrm{N}_{2}$ saturated $0.5 \mathrm{M} \mathrm{H}_{2} \mathrm{SO}_{4}$; scan rate, $20 \mathrm{mV} \mathrm{s}^{-1}$; $\mathrm{E}_{\text {start }}=$ open circuit potential. The arrow shows the scan direction.

As expected, the oxygen plasma treatment did not change the crystallographic structure of platinum black surfaces, since the temperature (room $\mathrm{T}^{\circ}$ ) of the oxygen plasma is not high enough to induce annealing of the surface. In addition, the presence of $\mathrm{PtO}_{2}$ could not be evidenced in the XRD spectra because these oxides are encountered only at the extreme surface (as shown by depth profile of XPS spectra) and they don't form a new bulk phase in the rough platinized platinum. Finally, the oxygen plasma treatment did not induce any changes in the morphology of Ptblack deposits, at least at the scale of high resolution SEM images.
Influence of the oxygen plasma treatment on the detection of several species

The effects of the oxygen plasma treatment on the oxidation waves of hydrogen peroxide and hydroquinone in PBS were studied (Figures 10a and 10b). A first observation was that in the condition, i.e. a large potential window, allowing the observation by cyclic voltammetry of two oxidation waves in PBS for both species, no clear and efficient effect of the plasma treatment was observed; transfer kinetics and thermodynamics were not improved. When focusing the study, by limiting the potential window, on the first oxidation wave, we observed variations of interest for mechanistic studies. As depicted in Figure 10 and detailed in Table 1, hydrogen peroxide and hydroquinone oxidation waves were displaced at lower half-wave potentials, typically a $50 \mathrm{mV}$-difference, and showed faster transfer kinetics with better defined voltammetric responses.

The difference of results between the two sets of experiments, as function of the potential window, is in agreement with the results of figure $5 \mathrm{~b}$ showing the role of the upper potential limit on surface oxide creation and modification. As demonstrated in Figure S2, when the electrode potential reaches at least $0.6 \mathrm{~V} v \mathrm{vs} . \mathrm{Ag} / \mathrm{AgCl}$ in PBS, the response of the surface changes, corresponding to a modification of the nature or distribution of platinum oxides. Indeed, $\mathrm{Pt}-\mathrm{O}$ oxides can be formed at higher potentials. Such an electrochemical annealing effect is well documented on polycrystalline platinum electrode ${ }^{[59,60]}$, and our measurements show that the process is also possible for platinum black surface in phosphate buffer. Hence, the catalytic effect of the oxygen plasma treatment is observed only for platinized electrodes that did not suffer a surface chemistry reconstruction at high potentials $(\mathrm{E}>0.6 \mathrm{~V})$, via the formation of Pt-O oxides. Since the first oxidation waves of hydrogen peroxide and hydroquinone are detected at potentials lower than $0.4 \mathrm{~V}$, valuable effects of the oxygen plasma treatment on platinum black can be observed. This shows eventually that the $\mathrm{PtO}_{2}$ surface oxides play a key role in the catalytic effects described above. Moreover, when storing the oxygen plasma treated platinized microelectrodes in MiliQgrade water, these oxides were stable for at least one week since the electrode responses were stable in terms of the oxidation waves features.

Table 1. Half-wave potential $\left(E_{1 / 2}\right.$ vs $\left.(\mathrm{Ag} / \mathrm{AgCl}) / \mathrm{V}\right)$ for the studied species before and after the oxygen plasma treatment

\begin{tabular}{lllll}
\hline \multirow{2}{*}{ Species } & \multicolumn{2}{c}{ Before plasma treatment } & \multicolumn{2}{c}{ After plasma treatment } \\
\cline { 2 - 5 } & $1^{\text {st }}$ wave $^{[\mathrm{a}]}$ & $1^{\text {st }}$ wave $^{[\mathrm{b}]}$ & $1^{\text {st }}$ wave $^{[\mathrm{a}]}$ & $1^{\text {st }}$ wave $^{[\mathrm{b}]}$ \\
\hline Hydroquinone & 0.100 & $\mathbf{0 . 0 8 0}$ & 0.090 & $\mathbf{0 . 0 2 5}$ \\
$\mathrm{H}_{2} \mathrm{O}_{2}$ & 0.200 & $\mathbf{0 . 2 7 5}$ & 0.230 & $\mathbf{0 . 2 4 0}$ \\
$\mathrm{O}_{2}{ }^{-}$ & -0.020 & - & -0.060 & - \\
\hline
\end{tabular}

[a] with surface reconstruction. [b] without surface reconstruction 
Finally, we extended the above study to the detection of another species of bioanalytical interest, superoxide radical anion. Superoxide is a major ROS, the mother species of at least $\mathrm{H}_{2} \mathrm{O}_{2}$ and $\mathrm{ONOO}^{-}$. It is involved in the physiological metabolism of all aerobic cells, but also in derived oxidative stress mechanisms. Although many electrochemical sensors have been developed for the detection of superoxide [11-13], the use of platinum black electrodes was not reported so far. We detected by cyclic voltammetry a clear single oxidation wave centered near $0 \mathrm{~V}$ vs. $\mathrm{Ag} / \mathrm{AgCl}$ for superoxide in basic phosphate buffer solutions. It is worth to mention that the mechanism of superoxide oxidation at platinum black electrodes cannot be included in the general mechanism described above because this species is stable only in basic solution ( $\mathrm{pH} \mathrm{12).} \mathrm{At} \mathrm{this} \mathrm{pH}$, the adsorption of phosphate (key step of the proposed mechanism) is severely hindered by the adsorption of hydroxyl anion. Nevertheless, we observed similarly that the oxygen plasma treatment could improve the detection of superoxide anion at platinum black electrodes, as the oxidation wave was displaced at even lower potentials $(-0.05 \mathrm{~V})$, with a lower background capacitive current after treatment (Figure 10c).

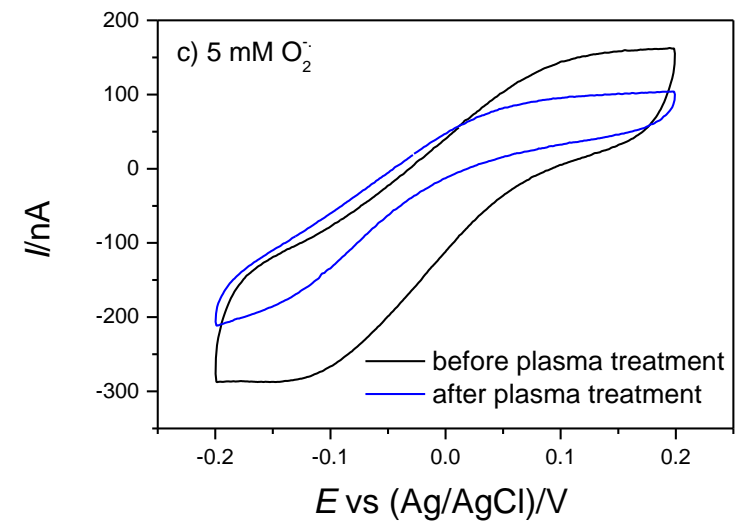

Figure 10. Cyclic voltammograms for the first wave of studied species before and after oxygen plasma treatment of the platinized microelectrode, without surface reconstruction. Experimental conditions: air equilibrated PBS pH 7.4 platinization charge, $800 \mu \mathrm{C}$ for all he species, except for $\mathrm{O}_{2}^{-\cdot}$ for which a platinization charge of $150 \mu \mathrm{C}$ was used.

\section{Conclusion}
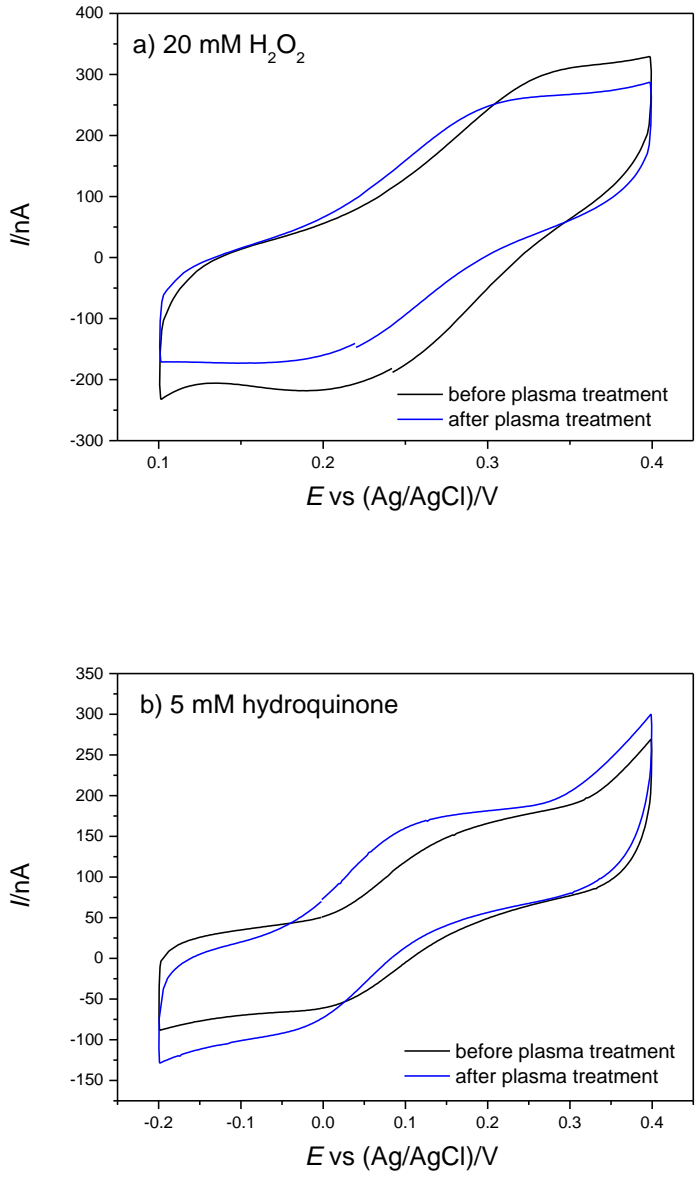

Amatore et al. have reported at many instances the analytical interests of a special-structured platinum surface, the platinum black one. This surface can be electrochemically deposited under excellent control on electrodes of various geometry and dimension, even on a single carbon nanotube (unpublished results). It was reported earlier that the Pt-black surface provides a very efficient detection of the major redox product of oxidases, hydrogen peroxide. However, the mechanism of its detection was poorly understood until now. In this framework, we showed herein that two oxidation processes can occur on the same Pt-black surface; the first one at low potentials, below the OCP, involves the adsorption of phosphates and the following adsorption of $\mathrm{H}_{2} \mathrm{O}_{2}$ before its fast oxidation. In addition, the thermodynamic and kinetic of this overall process can be improved under an oxygen plasma treatment. The locally generated surface oxides, $\mathrm{PtO}_{2}$, favor the catalysis of the process. Oppositely, they do not affect the second oxidation wave, which behaves as a pure-diffusion wave and provides much less sensitivity for $\mathrm{H}_{2} \mathrm{O}_{2}$ detection. These studies pave the way for further surface treatments of $\mathrm{Pt}$ black and deciphering of corresponding electrochemical mechanisms. The advantage of such surfaces over $\mathrm{Pt}$ nanoparticle-modified electrodes is the full control of surface roughness and area by electrodeposition, providing high sensitivity for measurements of biological responses on cells, tissue or organelles.

\section{Experimental Section}

Microelectrodes used in this study are denoted as such with respect to the platinum disk diameter that is in micrometer range $(25 \mu \mathrm{m})$ and not to the final body of the sealed Pt disk that was about $2 \mathrm{~mm}$ in diameter. The procedure for obtaining disk shaped microelectrodes consists in introducing the $25 \mu \mathrm{m}$ diameter platinum wire (Goodfellow, Pt 99.99\%) into 
the tapered end of a glass tube (soft glass), then heat it and seal it with a heating loop. The non-sealed end of the wire was connected to a millimetric steel wire using silver paste. The flat surface of the microdisk was obtained after polishing with a coarse and a fine grade polishing papers. A polishing step using $\mathrm{Al}_{2} \mathrm{O}_{3}$ particle suspension was not employed in this study.

Platinization of the microelectrodes was achieved by reducing $115 \mathrm{mM}$ hydrogen hexachloroplatinate (prepared in PBS buffer, see below) in the presence of $0.76 \mathrm{mM}$ lead acetate at $-60 \mathrm{mV}$ versus $\mathrm{Ag} / \mathrm{AgCl} / \mathrm{NaCl} 3 \mathrm{M}$ (this refence electrode has a potential of $0.209 \mathrm{~V}$ vs SHE). The electrodeposition was stopped when the total reduction charge reached $150 \mu \mathrm{C}$ or $800 \mu \mathrm{C}$. All chemicals were from Sigma-Aldrich. Superoxide solution was prepared using ice-cold $0.03 \mathrm{M} \mathrm{NaOH}$ and the obtained concentration was calculated following the protocol reported elsewhere [61] (Caution! potassium superoxide reacts violently with water). Decomposition of this species is neglected as the cyclic voltammetry measurements were taken as quickly as possible after the solution preparation

Platinized microelectrodes (also called black platinum electrodes) were exposed to oxygen plasma within so-called plasma cleaner (Harrick Plasma inc., plasma-flow PDCFMG). The exposure chamber was previously cleaned with acetone. After inserting the sample, the chamber was subjected to vacuum in order to reach a 100 mTorr pressure. $100 \%$ oxygen flow was then injected in the chamber in order to reach a final pressure of 750 mTorr. The plasma created in the chamber should be white coloured. After 20 min exposure, the chamber was opened and the sample was immediately soaked in MiliQ water.

The electrochemical measurements were carried out using a potentiostat (BioLogic inc. VSP-300, EC-Lab software, with a built-in impedance spectrometer) and a standard single compartment electrochemical cell. An $\mathrm{Ag} / \mathrm{AgCl} / \mathrm{NaCl} 3 \mathrm{M}$ electrode and a large platinum wire were used as reference and respectively counter electrodes. Electrochemical experiments were carried out in PBS buffer (10 mM phosphates, $138 \mathrm{mM}$ $\mathrm{NaCl}, 2.7 \mathrm{mM} \mathrm{KCl}, \mathrm{pH} 7.4)$. All the solutions of the studied compounds were prepared using this buffer. Cyclic voltammograms (CVs) were conducted at $20 \mathrm{mV} \mathrm{s}^{-1}$ scan rate over different potential windows and cycle 3 is represented in the Figures, if not mentioned otherwise (see Figures). Electrochemical impedance spectroscopy was recorded in the $50 \mathrm{kHz}-100 \mathrm{mHz}$ range, with a sinusoidal ac potential perturbation of 10 $\mathrm{mV}$ superimposed to the open circuit potential. Readings were taken at 15 discrete frequencies per decade.

A Thermo Fisher Scientific K-ALPHA spectrometer was used for surface analysis with a monochromatized AI Ka source $(\mathrm{hv}=1486.6 \mathrm{eV})$ and a 200 micrometer-size spot. The full spectra $(0-1100 \mathrm{eV})$ were obtained with constant pass energy of $200 \mathrm{eV}$ and the high resolution spectra $(\mathrm{C} 1 \mathrm{~s}, \mathrm{O} 1 \mathrm{~s}$, $\mathrm{Pt4f}$ ) at constant pass energy of $40 \mathrm{eV}$. Charge neutralisation was applied during analysis. Sputtering was performed with $\mathrm{Ar}^{+}$ions at $500 \mathrm{eV}$. High resolution spectra were fitted and quantified (Scofield sensitivity factors used for quantification) using the AVANTAGE software provided by Thermo Fisher Scientific. A SEM (FEG JEOL JSM 6700F) with an integrated EDX system was used for sample imaging before and after oxygen plasma treatment. X-ray diffraction (XRD) patterns were collected on a PANalitycal X'pert MPD-PRO Bragg-Brentano $\theta-\theta$ geometry diffractometer equipped with a secondary monochromator, a $3 \times 15$ positions sample changer and an X'celerator detector over an angular range of $2 \theta=8-80^{\circ}$. Each acquisition lasted for 3 hours. The $\mathrm{Cu}-\mathrm{Ka}$ radiation was generated at $45 \mathrm{KV}$ and $40 \mathrm{~mA}$ (lambda $=0.15418 \mathrm{~nm}$ ).

\section{Acknowledgements}

This work was financially supported by the French Agence nationale de la Recherche (ANR, PLASMAREGEN project, no. ANR-14-CE16-0007-01). The authors thanks to Eric Lebraud and Stanislav Pechev from the X-ray department of ICMCB for the acquisition of XRD spectra and to Christine Labrugère from PLACAMAT for the acquisition of XPS spectra.

Keywords: platinization • platinum black • oxygen plasma • hydrogen peroxide $\bullet$ hydroquinone $\bullet$ surface annealing

\section{References}

[1] T. Ruzgas, E. Csoregi, J. Emneus, L. Gorton, G. MarkoVarga, Analytica Chimica Acta 1996, 330, 123-138.

[2] E. Katz, I. Willner, Electroanalysis 2003, 15, 913-947.

[3] N. Bistolas, U. Wollenberger, C. Jung, F. W. Scheller, Biosensors \& Bioelectronics 2005, 20, 2408-2423.

[4] E. Katz, I. Willner, Chemphyschem 2004, 5, 1085-1104.

[5] M. Gerard, A. Chaubey, B. D. Malhotra, Biosensors \& Bioelectronics 2002, 17, 345-359.

[6] B. Krajewska, Enzyme and Microbial Technology 2004, 35, 126-139.

[7] T. Kuila, S. Bose, P. Khanra, A. K. Mishra, N. H. Kim, J. H. Lee, Biosensors \& Bioelectronics 2011, 26, 4637-4648

[8] S. Hrapovic, Y. L. Liu, K. B. Male, J. H. T. Luong, Analytical Chemistry 2004, 76, 1083-1088.

[9] S. J. Guo, D. Wen, Y. M. Zhai, S. J. Dong, E. K. Wang, Acs Nano 2010 4, 3959-3968

[10] M. H. Yang, Y. H. Yang, Y. L. Liu, G. L. Shen, R. Q. Yu, Biosensors \& Bioelectronics 2006, 21, 1125-1131.

[11] S. K. Kim, D. Kim, J. M. You, H. S. Han, S. Jeon, Electrochimica Acta 2012, 81, 31-36

[12] X. Zhu, X. H. Niu, H. L. Zhao, J. Tang, M. B. Lan, Biosensors \& Bioelectronics 2015, 67, 79-85

[13] M. Cortina-Puig, A. C. H. Scangas, Z. S. Marchese, S. Andreescu, J. L. Marty, C. Calas-Blanchard, Electroanalysis 2010, 22, 2429-2433.

[14] H. A. Gasteiger, S. S. Kocha, B. Sompalli, F. T. Wagner, Applied Catalysis B-Environmental 2005, 56, 9-35.

[15] S. H. Joo, S. J. Choi, I. Oh, J. Kwak, Z. Liu, O. Terasaki, R. Ryoo, Nature 2001, 412, 169-172

[16] B. Lim, M. J. Jiang, P. H. C. Camargo, E. C. Cho, J. Tao, X. M. Lu, Y. M. Zhu, Y. N. Xia, Science 2009, 324, 1302-1305.

[17] Y. Li, C. Sella, F. Lemaître, M. Guille Collignon, L. Thouin, C. Amatore, Electroanalysis 2013, 25, 895-902

[18] C. Amatore, S. Arbault, C. Bouton, K. Coffi, J.-C. Drapier, H. Ghandour, Y. Tong, Chembiochem 2006, 7, 653-661.

[19] C. Amatore, S. Arbault, D. Bruce, P. D. Oliveira, Chemistry-European Journal 2001, 7, 4171-4179.

[20] C. Amatore, S. Arbault, A. C. W. Koh, Anal. Chem. 2010, 82, 1411-1419.

[21] Y. Li, C. Sella, F. Lemaitre, M. Guille-Collignon, L. Thouin, C. Amatore, Electrochimica Acta 2014, 144, 111-118.

[22] S. Yamagiwa, A. Fujishiro, H. Sawahata, R. Numano, M. Ishida, T. Kawano, Sensors and Actuators B: Chemical 2015, 206, 205-211.

[23] Y.-F. Rui, J.-Q. Liu, B. Yang, C.-S. Yang, D.-X. Wei, Journal of Applied Electrochemistry 2012, 43, 301-308.

[24] S. Mailley, M. Hyland, P. Mailley, J. A. McLaughlin, E. T. McAdams, Bioelectrochemistry 2004, 63, 359-364

[25] C. S. Kim, S. M. Oh, Electrochimica Acta 1996, 41, 2433-2439.

[26] S. Gu, Y. Lu, Y. Ding, L. Li, H. Song, J. Wang, Q. Wu, Biosensors \& Bioelectronics 2014, 55, 106-112. 
[27] D. M. Im, D. H. Jang, S. M. Oh, C. Striebel, H. Wiemhiifer, G. Gauglitz, W. Gijpel, Sensors \& Actuators B 1995, 149, 24-25.

[28] J. Wang, N. V. Myung, M. Yun, H. G. Monbouquette, Journal of Electroanalytical Chemistry 2005, 575, 139-146.

[29] J. I. R. De Corcuera, J. R. Powers, Journal of Electroanalytical Chemistry 2005, 575, 229-241.

[30] H.-K. Seo, D.-J. Park, J.-Y. Park, Thin Solid Films 2008, 516, 5227-5230.

[31] L. Ming, T. Peng, Y. Tu, Microchimica Acta 2015, 183, 305-310.

[32] L. Qiang, S. Vaddiraju, J. F. Rusling, F. Papadimitrakopoulos, Biosensors \& Bioelectronics 2010, 26, 682-688.

[33] S. B. Hall, E. A. Khudaish, A. L. Hart, Electrochimica Acta 1998, 43 , 2015-2024.

[34] S. B. Hall, E. A. Khudaish, A. L. Hart, Electrochimica Acta 1998, 43, 579 588.

[35] S. B. Hall, E. A. Khudaish, A. L. Hart, Electrochimica Acta 1999, 44 4573-4582.

[36] S. B. Hall, E. A. Khudaish, A. L. Hart, Electrochimica Acta 1999, 44, 2455-2462.

[37] S. B. Hall, E. A. Khudaish, A. L. Hart, Electrochimica Acta 2000, 45, 3573-3579.

[38] a. Hickling, W. H. Wilson, Journal of The Electrochemical Society 1951, 98, 425 .

[39] I. Katsounaros, W. B. Schneider, J. C. Meier, U. Benedikt, P. U. Biedermann, A. a. Auer, K. J. J. Mayrhofer, Physical Chemistry Chemical Physics 2012, 14, 7384.

[40] A. Kicela, S. Daniele, Talanta 2006, 68, 1632-1639.

[41] S. Ben-Amor, A. Devin, M. Rigoulet, N. Sojic, S. Arbault, Electroanalysis 2013, 25, 656-663

[42] J. S. Hammond, N. Winograd, Journal of Electroanalytical Chemistry 1977, 78, 55-69.

[43] N.-H. Li, S.-G. Sun, S.-P. Chen, Journal of Electroanalytical Chemistry 1997, 430, 57-67.

[44] S. Z. Zou, H. Y. H. Chan, C. T. Williams, M. J. Weaver, Langmuir 2000 , 16, 754-763.
[45] A. E. Bolzan, A. J. Arvia, Journal of Electroanalytical Chemistry 1994 375, 157-162.

[46] H. Takahashi, M. Sagihara, M. Taguchi, International Journal of Hydrogen Energy 2014, 39, 18424-18432

[47] W. Jung, J. J. Kim, H. L. Tuller, Journal of Power Sources 2015, 275 , 860-865.

[48] Z. Li, P. Beck, D. A. A. Ohlberg, D. R. Stewart, R. S. Williams, Surface Science 2003, 529, 410-418

[49] L. K. Ono, J. R. Croy, H. Heinrich, B. R. Cuenya, The Journal of Physical Chemistry C 2011, 115, 16856-16866.

[49] S. Ben-Amor, A. Devin, M. Rigoulet, N. Sojic, S. Arbault, Electroanalysis 2013, 25, 656-663.

[50] I. Katsounaros, W. B. Schneider, J. C. Meier, U. Benedikt, P. U. Biedermann, A. A. Auer, K. J. J. Mayrhofer, Physical Chemistry Chemical Physics 2012, 14, 7384-7391.

[51] J. M. Feliu, M. J. Valls, A. Aldaz, M. A. Climent, J. Clavilier, Journal of Electroanalytical Chemistry 1993, 345, 475-481.

[52] R. Gisbert, G. García, M. T. M. Koper, Electrochimica Acta 2010, 55 7961-7968.

[53] J. Mostany, P. Martínez, V. Climent, E. Herrero, J. M. Feliu, Electrochimica Acta 2009, 54, 5836-5843.

[54] F. C. Nart, Iwasita, T., Electrochimica Acta 1992, 37, 385-391.

[55] G. C. Allen, P. M. Tucker, A. Capon, R. Parsons, Journal of Electroanalytical Chemistry and Interfacial Electrochemistry 1974, 50 335-343.

[56] J. J. Blackstock, D. R. Stewart, Z. Li, Applied Physics A: Materials Science and Processing 2005, 80, 1343-1353.

[57] H. Angerstein-Kozlowska, B. E. Conway, W. B. A. Sharp, Journal of Electroanalytical Chemistry and Interfacial Electrochemistry 1973, 43, 9 36.

[58] B. E. Conway, Progress in Surface Science 1995, 49, 331-452.

[59] M. Zorko, B. Jozinović, M. Bele, N. Hodnik, M. Gaberšček, Ultramicroscopy 2014, 140, 44-50.

[60] M. Szklarczyk, J. O. M. Bockris, Surface Science 1991, 241, 54-60.

[61] S. Marklund, The journal of biological chemistry 1976, 251, 7504-7507. 
Entry for the Table of Contents (Please choose one layout)

Layout 1:

\section{ARTICLE}

Oxygen plasma treatment of Pt-black surface improves the detection of hydrogen peroxide in PBS by acting on the adsorption of phosphates.
V. Badets, J. Pandard, N. Sojic and S. Arbault

Page No. - Page No.

Deciphering the Platinized Surface Reactivity to Improve the Detection of Hydrogen Peroxide in Bioanalyses 